Open Access

\title{
Low-dose CT coronary angiography for assessment of coronary artery disease in patients with type 2 diabetes - A cross- sectional study
}

Geir Reinvik Ulimoen ${ }^{1 *}$, Anne Pernille Ofstad ${ }^{2}$, Knut Endresen ${ }^{3}$, Lars Gullestad ${ }^{3,4}$, Odd Erik Johansen ${ }^{2}$ and Arne Borthne $e^{1,4}$

\begin{abstract}
Background: Silent coronary artery disease (CAD) is prevalent in type 2 diabetes mellitus (T2DM). Although coronary computed tomography angiography (CCTA) over recent years has emerged a useful tool for assessing and diagnosing CAD it's role and applicability for patients with T2DM is still unclarified, in particular in asymptomatic patients. We aimed to assess the role of CCTA in detecting and characterizing CAD in patients with T2DM without cardiac symptoms when compared to gold standard invasive coronary angiography (ICA).

Methods: This was a cross-sectional analysis of patients with T2DM without symptomatic CAD enrolled in the Asker and Baerum Cardiovascular Diabetes Study who, following clinical examination and laboratory assessment, underwent subsequently CCTA and ICA.

Results: In total 48 Caucasian patients with T2DM (36 men, age $64.0 \pm 7.3$ years, diabetes duration $14.6 \pm 6.4$ years, HbA1c $7.4 \pm 1.1 \%$, BMI $29.6 \pm 4.3 \mathrm{~kg} / \mathrm{m}^{2}$ ) consented to, and underwent, both procedures (CCTA and ICA). The population was at intermediate cardiovascular risk (mean coronary artery calcium score 269, $75 \%$ treated with antihypertensive therapy). ICA identified a prevalence of silent CAD at $17 \%$ whereas CCTA $35 \%$. CCTA had a high sensitivity (100 \%) and a high negative predictive value (100 \%) for detection of patients with CAD when compared to ICA, but the positive predictive value was low (47\%).

Conclusions: Low-dose CCTA is a reliable method for detection and exclusion of significant CAD in T2DM and thus may be a useful tool for the clinicians. However, a low positive predictive value may limit its usefulness as a screening tool for all CAD asymptomatic patients with T2DM. Further studies should assess the applicability for risk assessment beyond the evaluation of the vascular bed.
\end{abstract}

Keywords: Type 2 diabetes mellitus, Cardiovascular complications, Imaging, CT angiography, Coronary artery calcification, Risk assessment

\footnotetext{
* Correspondence: geir.ulimoen@online.no

Odd Erik Johansen and Arne Borthne: co-senior authors.

'Department of Radiology, Akershus University Hospital, PB 1000, 1478

Lorenskog, Norway

Full list of author information is available at the end of the article
}

(c) 2015 Ulimoen et al. Open Access This article is distributed under the terms of the Creative Commons Attribution 4.0 International License (http://creativecommons.org/licenses/by/4.0/), which permits unrestricted use, distribution, and reproduction in any medium, provided you give appropriate credit to the original author(s) and the source, provide a link to the Creative Commons license, and indicate if changes were made. The Creative Commons Public Domain Dedication waiver (http://creativecommons.org/publicdomain/zero/1.0/) applies to the data made available in this article, unless otherwise stated. 


\section{Background}

Type 2 diabetes mellitus (T2DM) is a chronic metabolic disease that represents a major public health concern. T2DM affects more than 382 million people world-wide and the prevalence is expected to increase substantially [1]. Cardiovascular (CV) disease is the most common cause of death in patients with T2DM [2,3]. The prevalence of undiagnosed coronary artery disease (CAD) among asymptomatic patients with T2DM is high and independent assessments using different diagnostic techniques, i.e., invasive coronary angiography (ICA) [4] or maximum stresstest [5] have found that more than 1 in 5 adults with T2DM have significant CAD. The diagnosis of CAD may be missed or delayed in these patients since the typical symptoms of CAD are often absent in patients with longstanding T2DM, which in turn further increases their risk for CV events. To potentially prevent CV events it may therefore be important to detect subclinical CAD in T2DM to enable appropriate intervention to reduce the risk of fatal and non-fatal cardiac events.

Findings to date to not support widespread screening for CAD in patients with T2DM, but this may partly be related to lack of a reliable and cost-effective screening tool [6].

ICA has been the accepted gold standard method for assessing the presence, localization, and severity of CAD, but has a substantial procedural cost and is an invasive method associated with a risk for complications. Coronary computed tomography angiography (CCTA) has over recent years emerged as an alternative to ICA for CAD assessment and the 64-slice generation scanners multidetector computer tomography (MDCT) is now considered to have high diagnostic performance for detection of significant coronary stenosis [7] in different populations. So far only few studies have assessed the role of MDCT in patients with T2DM $[8,9]$, and its full potential is not fully understood, in particular in light of studies being suggestive of a reduced diagnostic performance of MDCT compared to non-T2DM populations [10]. Thus, the role of CCTA is considered uncertain in asymptomatic high-risk patients like patients with T2DM [11].

In this study we aimed to assess the role of CCTA in detecting and characterizing CAD in patients with T2DM without cardiac symptoms. To provide robustness of using CCTA, all patients underwent both CCTA and gold standard ICA, and to our knowledge this is the first study to employ both strategies in asymptomatic patients with T2DM.

\section{Methods}

\section{Study population}

Caucasian subjects with T2DM without cardiac symptoms who were enrolled in the Asker and Baerum Cardiovascular Diabetes (ABCD) study in 2002-2004
[12] and still alive, were eligible for participation in this 7-year cross-sectional follow-up study (ABCD-2). Classification of subjects as being asymptomatic was based on patient history and clinical assessment (i.e., free from cardio-pulmonary symptoms) [13]. In addition to T2DM, diagnosed in accordance with diagnostic criteria by the World Health Organization [14], the inclusion criteria in the ABCD-study were age 18-75 years and at least one additional $\mathrm{CV}$ risk factor (hypertension [treated or $24 \mathrm{~h}$ systolic/diastolic blood pressure $\geq 140 / 90 \mathrm{mmHg}$, dyslipidaemia [treated or total cholesterol $\geq 5.0 \mathrm{mmol} / \mathrm{L}$, HDL-cholesterol $\leq 1.0 \mathrm{mmol} / \mathrm{L}$ in men, or $\leq 1.1 \mathrm{mmol} / \mathrm{L}$ in women or triglycerides $\geq 2.0 \mathrm{mmol} / \mathrm{L}]$, past or prior smoking, premature CAD in $1^{\text {st }}$ degree family [male $<55$ years, female $<65$ years], or microalbuminuria). Exclusion criteria in this imaging follow-up study were irregular heart rate, pregnancy, known allergy to iodinated contrast medium and elevated serum creatinine (female $>120 \mu \mathrm{mol} / \mathrm{L}$, male $>130 \mu \mathrm{mol} / \mathrm{L})$.

The study complied with the Declaration of Helsinki and was approved by the Regional Committee for Medical and Health Research Ethics. All participating patients gave written informed consent.

\section{Investigation and study procedures}

Following an assessment of medical history, clinical examination including cardiopulmonary exercise testing and laboratory assessment, patients were voluntarily referred for subsequently assessments with CCTA or ICA regardless of the results of the non-invasive tests. Both CAD imaging modalities had to be completed within a 6 month time window by experienced radiologists or cardiologists.

\section{Cardiopulmonary exercise test}

Exercise induced cardiac ischemia was assessed using a modified conventional maximum symptom-limited 1-min incremental cardiopulmonary exercise test on a cycle ergometer (Siemens-Elema, Germany). Cycling frequency had to be at least 60 rounds pr minute. The criterion for classifying a test as positive was the traditional $\geq 1 \mathrm{~mm}$ STsegment depression observed in two adjacent leads.

\section{Laboratory assessment}

Peripheral venous blood samples were drawn in the morning after an overnight fast and routine laboratory parameters were immediately analyzed by the local laboratory. For all assays, the intra-and inter assay coefficients of variation were $<10 \%$.

\section{Coronary Computed Tomography Angiography (CCTA)}

CCTA was performed at Akershus University Hospital, Lørenskog, Norway, using a 256-slice scanner (Brilliance iCT, Philips Healthcare, Cleveland, OH, USA). Metoprolol 
was intravenously administered with a titration dose up to $15 \mathrm{mg}$ in all patients with heart rate $>70 \mathrm{bpm}$. A low-dose scout image followed by unenhanced prospectively ECGtriggered coronary artery calcium $(\mathrm{CAC})$ scoring acquisition. Imaging parameters includes $\mathrm{X}$-ray tube voltage $120 \mathrm{kV}$, detector configuration $32 \times 0.625 \mathrm{~mm}$, gantry rotation time $0.33 \mathrm{~s}$, field of view $250 \mathrm{~mm}$, reconstructed slice thickness $2.5 \mathrm{~mm}$ and increment $2.5 \mathrm{~mm}$. Angiographic acquisition was performed using a prospectively ECG-triggered step-and-shoot mode and the contrast medium iomeprol (Iomeron $400 \mathrm{mg} / \mathrm{ml}$, Bracco Imaging SpA). A detector configuration of $128 \times 0.625 \mathrm{~mm}$ with dual z-focal spot positions was used. Gantry rotation time was $0.27 \mathrm{~s}$, temporal resolution $135 \mathrm{msec}$ and X-ray tube voltage was $120 \mathrm{kV}$.

Both calcium scoring acquisition and angiographic acquisition were started at a predefined time point at $75 \%$ of the RR interval corresponding to a physiological phase of ventricular diastasis, with the tube output turned off during the other phases of the RR interval. The effective radiation dose of the $\mathrm{CT}$ exam was estimated by the product of the dose length product from the dose report of the CT scanner and a conversion coefficient for the chest $\left(\mathrm{k}=0.014 \mathrm{mSv}\right.$ * $\left.\mathrm{mGy}-1{ }^{*} \mathrm{~cm}-1\right)$ [15].

Analysis was performed by two experienced radiologist in consensus, using specialized software on a dedicated workstation (Comprehensive Cardiac Analysis, Extended Brilliance Workspace V4.02, Philips Healthcare, Cleveland, $\mathrm{OH}, \mathrm{USA}$ ) including semi-automated software for analysis of Agatston calcium score [16]. The interpreters were blinded for the results of ICA and non-invasive tests. For analysis, the coronary arteries were segmented into a 15segment American Heart Association (AHA) model [17] and segments with a luminal diameter $\geq 1 \mathrm{~mm}$ were evaluated. Image quality was ranked using a 4-point scale (1: good image quality, vessels with sharp edges without discontinuity and artifacts; 2: adequate image quality, vessels with minor artifacts or slight blurring; 3: decreased image quality, evaluation difficult but still possible; 4: noninterpretable). Calcifications were ranked using a 3-point scale (1: no calcifications; 2: minor calcifications; 3: severe calcifications). All interpretable segments were scored with a 4-point scale (0: no stenosis or $\leq 24 \%$ lumen reduction; 1 : $25-49 \%$ stenosis; 2 ; 50-74 \% stenosis; $3: \geq 75 \%$ stenosis). A stenosis of $\geq 50 \%$ was considered significant.

\section{Invasive coronary angiography}

ICA was performed by radial or femoral approach according to the standard Judkins technique using $6 \mathrm{~F}$ diagnostic catheters (Cordis Corporation, Miami, FL, USA) and the contrast medium iodixanol (Visipaque $320 \mathrm{mg} / \mathrm{ml}$, Amersham Health, GE Healthcare AS, Oslo, Norway). The angiograms were performed at the catheterization lab at Oslo University Hospital Rikshospitalet, Oslo, Norway and analyzed by an experienced cardiologist who was blinded to the results of non-invasive tests and CCTA. All angiograms were evaluated by visual analysis supported by a quantitative coronary analysis (QCA) program (Sectra Cardiology Package 1.0, Sectra Imtec, Sweden) with similar segment model and stenosis grading as for CCTA.

\section{Statistics}

Data are reported as frequencies or mean with standard deviation. Correlations analysis between calcium scores and baseline HbA1c and duration of T2DM was performed (Spearman's correlation). Cohen's kappa statistics were used to describe concordance between the methods interpreted by the guidelines of Landis and Koch [18]. Sensitivity, specificity, and positive and negative predictive values with corresponding $95 \%$ confidence intervals (CI) were calculated for the detection of significant ( $>50 \%)$ coronary artery stenoses with CCTA, using ICA as the gold standard and Vassarstats (Vassar College, Poughkeepsie, N.Y., USA) for statistical analysis. For all other statistical analysis, IBM SPSS Version 22 was used.

\section{Results}

\section{Demographics}

Of 93 patients consenting to participate in ABCD-2, 56 patients had no contraindications to the imaging procedures and consented to perform both CCTA and ICA. In eight patients $\mathrm{CT}$ angiography was not performed, because of calcium score $>1000$, rendering 48 patients eligible for analysis. The patient population studied was obese (mean BMI $29.6 \mathrm{~kg} / \mathrm{m} 2$ ) and middle-aged (mean age 64 years) with a long history of T2DM (mean duration 15.6 years), not at optimal glycemic control (mean HbA1c $7.4 \%)$. The majority were males (75 \%). Further characteristics are given in Table 1.

\section{Imaging assessments}

In total $99 \%$ (588 out of 594) of coronary segments with a luminal diameter $\geq 1 \mathrm{~mm}$ from the full patient population were eligible for analysis with CCTA. Only 6 segments were non-interpretable, mainly because of severe artifacts from pacemaker electrodes. Mean Agatston score was 269, but ranged from 0 to 976 and this did not correlate with neither diabetes duration $(\mathrm{r}=0.05, \mathrm{p}=0.75)$ or HbA1c $(r=-0.14, p=0.35)$. Image quality and degree of calcifications are detailed in Table 2. In analyzing the 588 segments, CCTA had a sensitivity of $90 \%$ (9 of 10) and a specificity of $96 \%$ (557 of 578) for detection of coronary stenosis $\geq 50 \%$ using ICA as gold standard (Table 3 ). The positive predictive value was $30 \%$ ( 9 of 30 ) and the negative predictive value $99 \%$ (556 of 557). Degree of stenosis per segment analysis and maximum degree of any stenosis per patient analysis are given in Table 3. CCTA wrongly classified 21 segments (3.8\%) as having significant 
Table 1 Baseline characteristics of the study participants

Number

Background information

Gender (male, $n$ (\%)

Age (years), mean $\pm \mathrm{SD}$ (range)

Body Mass Index $\left(\mathrm{kg} / \mathrm{m}^{2}\right)$, mean \pm SD (range)

T2DM duration (years), mean \pm SD (range)

Medical history and medications

History of smoking, $n$ (\%)

Family history of premature CAD ( $1^{\text {st }}$ degree relative), $n(\%)$

Any medication for hypertension, $n(\%)$

Any lipidlowering medication, $n$ (\%)

Any blood glucose lowering medication, $n$ (\%)

-Any use of insulin, $n$ (\%)

Laboratory and clinically assessment

HbA1c (\%), mean \pm SD

Serum creatinine $(\mu \mathrm{mol} / \mathrm{L})$, mean $\pm \mathrm{SD}$ (range)

Total cholesterol $(\mathrm{mmol} / \mathrm{L})$, mean $\pm \mathrm{SD}$

$\mathrm{LDL}$ cholesterol $(\mathrm{mmol} / \mathrm{L})$, mean $\pm \mathrm{SD}$

$\mathrm{HDL}$ cholesterol (mmol/L), mean $\pm \mathrm{SD}$

Triglycerides $(\mathrm{mmol} / \mathrm{L})$, mean $\pm \mathrm{SD}$

Systolic blood pressure $(\mathrm{mmHg})$, mean \pm SD

Diastolic blood pressure $(\mathrm{mmHg})$, mean $\pm \mathrm{SD}$

Heart rate (bpm), mean \pm SD

Exercise ECG

- Positive, $n(\%)$

- Inconclusive, $n(\%)$

- Negative, $n(\%)$

\section{8}

$36(75 \%)$

$64.0 \pm 7.3(41.4-76,7)$

$29.6 \pm 4.3(21.7-39.7)$

$14.6 \pm 6.4(6.8-37.7)$

$19(39.6 \%)$

$24(50 \%)$

$36(75 \%)$

$38(79 \%)$

$46(96 \%)$

$9(18.7 \%)$

$7,4 \pm 1.1$

$71.4 \pm 16.7(42-117)$

$4.3 \pm 1.0$

$2.4 \pm 0.8$

$1.4 \pm 0.4$

$1.3 \pm 0.5$

$138 \pm 17$

$79 \pm 8$

$73 \pm 13$

$4(8.3 \%)$

$11(22.9 \%)$

$33(68.8 \%)$

Table 2 Coronary CTA, scan characteristics and results

\begin{tabular}{lc}
\hline Number of patients, $n$ & 48 \\
\hline Intravenous $\beta$-blocker given, $n$ (\%) & $18(37.5 \%)$ \\
Heart rate during scan, mean \pm SD (range) & $63.7 \pm 7.6(49-88)$ \\
Radiation dose (mSv), mean \pm SD (range) & $3.8 \pm 0.7(2.5-5.0)$ \\
Agatston score, mean \pm SD (range) & $269.0 \pm 292.8(0-976)$ \\
Image quality per segment, $n$ (\%) & $420(71 \%)$ \\
1. Good & $132(23 \%)$ \\
2. Adequate & $36(6 \%)$ \\
3. Decreased & \\
Degree of calcifications per segment, $n(\%)$ & $374(64 \%)$ \\
1. None & $171(29 \%)$ \\
2. Minor & $43(7 \%)$ \\
3. Severe & \\
\hline
\end{tabular}


Table 3 Results of CCTA and ICA

\begin{tabular}{lll}
\hline Diagnostic accuracy of CCTA using ICA as gold standard & Per segment & Per patient \\
- Sensitivity, \% (Cl) & $90 \%(54-99)$ & $100 \%(60-100)$ \\
- Spesificity, \% (Cl) & $96 \%(94-98)$ & $78 \%(61-89)$ \\
- Positive predictice value, \% (Cl) & $30 \%(15-50)$ & $47 \%(24-72)$ \\
- Negative predictive value, \% (Cl) & $99 \%(99-100)$ & $100 \%(86-100)$ \\
Degree of stenosis $n$ (\%), per segment analysis & CCTA & ICA \\
0. No stenosis or $\leq 24 \%$ lumen reduction & $447(76.0 \%)$ & $553(94.0 \%)$ \\
1. $25-49 \%$ stenosis & $110(18.7 \%)$ & $25(4.3 \%)$ \\
2. $50-74 \%$ stenosis & $29(4.9 \%)$ & $9(1.5 \%)$ \\
3. $75 \%$ stenosis & $2(0.4 \%)$ & $1(0.2 \%)$ \\
Maximum degree of any stenosis, $n(\%)$, per patient analysis & CCTA & ICA \\
0. No stenosis or $\leq 24 \%$ lumen reduction & $10(20.8 \%)$ & $28(58.3 \%)$ \\
1. $25-49 \%$ stenosis & $21(43.8 \%)$ & $12(25.0 \%)$ \\
2. $50-74 \%$ stenosis & $15(31.3 \%)$ & $7(14.6 \%)$ \\
3. $\geq 75 \%$ stenosis & $2(4.2 \%)$ & $1(2.1 \%)$ \\
\hline
\end{tabular}

stenosis. Of these 21 segments ICA classified 10 segments with 25-49\% stenosis and the remaining 11 segments without any stenosis ( $\leq 24 \%$ lumen reduction). All these 21 segments were found to have either severe calcifications or a combination of calcifications and minor artifacts on CCTA.

In a per patient analysis, $17 \%$ (8 of 48 ) had at least one stenosis $\geq 50 \%$ in any segment at ICA. CCTA correctly identified all these patients, corresponding to a sensitivity of $100 \%$. Specificity was $78 \%$, positive predictive value $47 \%$, and negative predictive value $100 \%$. Estimated Kappa was 0,53, giving moderate agreement between the methods.

At the maximum exercise test, the mean achieved work capacity was $143 \pm 44$ Watts. 15 patients (31 \%) had signs of silent ischemia with positive or inconclusive test. When comparing silent ischemia as detected on the maximum exercise test versus CCTA and ICA estimated Kappa were 0,16 and 0,17 respectively, yielding poor agreement.

\section{Discussion}

This study assessed the applicability of using a modern non-invasive imaging modality to detect significant CAD in an intermediate $\mathrm{CV}$ risk cohort of patients with T2DM and compared its results with the gold standard for assessing this, namely ICA. This study, to the best of our knowledge, is the first that have screened asymptomatic patients with both CCTA and ICA. The main finding of our study was that 256-slice CCTA with stepand-shoot technique provides excellent sensitivity and yields a high negative predictive value for excluding significant CAD in patients with T2DM, whereas the specificity and positive predictive value were lower $(78 \%$ and $47 \%$, respectively). These data are in agreement with results of other assessments on sensitivities in patients with low degree of vasculopathy, i.e. low calcium scores [19]. Our study also shows that the technique provides good feasibility with nearly all coronary segments eligible for analysis. Radiation dose is lower than with earlier generation CT scanners [20] and may be further reduced with newer techniques like iterative reconstruction [21, 22]. Our data suggested that despite a mean T2D duration of 15 years, mean Agatston score was 269, indicating that the population still was at intermediate $\mathrm{CV}$ risk, and not too advanced, as one could have expected based on the lengthy diabetes duration [23].

CCTA is well known to yield many false positives, but the low positive predictive values in our study seems inferior to most other reports although the results are varying [24]. There may be several contributions to this. Positive and negative predictive values are generally influenced by prevalence of disease, and the low prevalence of significant CAD in this study would contribute to lower positive predictive value than in studies with higher prevalence. The coronary plaque burden and coronary calcium score are generally higher in diabetic than in non-diabetic patients $[19,25]$ and since calcified plaques can lead to overestimation of lesion severity [26] this may contribute to lower positive predictive value for CCTA in a diabetic population than in a non-diabetic population. Some studies have shown smaller coronary vessel calibre in patients with $\mathrm{T} 2 \mathrm{DM}$ as compared to those without $[27,28]$, and this may affect the diagnostic accuracy of CCTA. Reduced diagnostic performance of CCTA in patients with T2DM is reported in the only known study comparing with patients without T2DM [10], but this study included mainly symptomatic patients and the prevalence of obstructive CAD was high. On the other side, a mean CAC value of 269 and $18 \%$ patients with zero CAC score would also render CCTA a suboptimal test to rule out obstructive CAD among symptomatic patients [19].

The major established indications for use of CCTA are within groups of symptomatic patients with low or intermediate pretest probability of obstructive $\mathrm{CAD}$, and in 
some pre- and postoperative settings [11]. A recent meta-analysis supports the use of CCTA as a first imaging test for low- and intermediate-risk patients presenting to the emergency department with chest pain [29]. The role of CCTA remains uncertain in asymptomatic high-risk patients like patients with T2DM, and even if there are reports finding a prognostic value of CCTA $[8,9]$ there is another recent study reporting that use of CCTA to screen asymptomatic patients with T2DM do not improve clinical outcome [30]. One study in patients with T2DM and mild anginal complaints demonstrated a crucial impact of ischemia on cardiac event rate and showed a prognostic value of myocardial perfusion scintigraphy (MPS [31], and a possible strategy may be to perform supplementary MPS in asymptomatic patients with positive CCTA. Another possible future improvement of screening CCTA may be a combination with computed tomography myocardial perfusion imaging, as there are recent promising reports about this method $[32,33]$, or to combine results of CCTA with prognostic biomarkers [34].

The relatively small number of included patients is a limitation of the generalizability of the study results, including the relatively low proportion of female patients.

\section{Conclusions}

Low-dose CCTA provides excellent sensitivity and negative predictive value in detecting and excluding significant CAD in patients with T2DM without known or suspected CAD. The usefulness of this method as a screening tool in asymptomatic intermediate risk patients like in T2DM may be limited by a rather low positive predictive value.

\section{Abbreviations}

CAC: coronary artery calcium.; CAD: coronary artery disease; CCTA: coronary computed tomography angiography; CV: cardiovascular; ICA: invasive coronary angiography; MDCT: multidetector computer tomography; T2DM: type 2 diabetes mellitus.

\section{Competing interests}

APO and OEJ are employees of Boehringer Ingelheim. The authors declare that they have no other competing interests.

\section{Authors' contributions}

$G R U, A P O, L G, O E J$ and $A B$ contributed in the conception and design of the study and in drafting of the manuscript. GRU and $A B$ performed and interpreted all CCTA examinations. KE interpreted all ICA examinations. GRU, $A P O, O E J$ and $A B$ contributed in analysis of study data. GRU and OEJ drafted the manuscript. All authors revised and approved the final manuscript.

\section{Acknowledgements}

This study was completely funded by research grants from the South-Eastern Norway Regional Health Authority.

\footnotetext{
Author details

${ }^{1}$ Department of Radiology, Akershus University Hospital, PB 1000, 1478 Lorenskog, Norway. ${ }^{2}$ Department of Medical Research, Bærum Hospital, Vestre Viken Hospital Trust, 3004 Drammen, Norway. ${ }^{3}$ Department of Cardiology, Oslo University Hospital, Rikshospitalet, 0372 Oslo, Norway. ${ }^{4}$ University of Oslo, Oslo, Norway.
}

Received: 20 July 2015 Accepted: 6 November 2015

Published online: 14 November 2015

\section{References}

1. IDF Diabetes Atlas. In., 6th edn. Brussels, Belgium:International Diabetes Federation; 2013. Available from: www.idf.org/diabetesatlas

2. Lorber D. Importance of cardiovascular disease risk management in patients with type 2 diabetes mellitus. Diabetes Metab Syndr Obes. 2014;7:169-83.

3. Stamler J, Vaccaro O, Neaton JD, Wentworth D. Diabetes, other risk factors, and 12-yr cardiovascular mortality for men screened in the Multiple Risk Factor Intervention Trial. Diabetes Care. 1993;16(2):434-44.

4. Johansen OE, Birkeland KI, Orvik E, Flesland O, Wergeland R, Ueland T, et al. Inflammation and coronary angiography in asymptomatic type 2 diabetic subjects. Scand J Clin Lab Invest. 2007;67(3):306-16.

5. Wackers FJ, Young LH, Inzucchi SE, Chyun DA, Davey JA, Barrett EJ, et al. Detection of silent myocardial ischemia in asymptomatic diabetic subjects: the DIAD study. Diabetes Care. 2004;27(8):1954-61.

6. Upchurch CT, Barrett EJ. Clinical review: Screening for coronary artery disease in type 2 diabetes. J Clin Endocrinol Metab. 2012;97(5):1434-42.

7. Janne d'Othee B, Siebert U, Cury R, Jadvar H, Dunn EJ, Hoffmann U. A systematic review on diagnostic accuracy of CT-based detection of significant coronary artery disease. Eur J Radiol. 2008;65(3):449-61.

8. Cademartiri F, Seitun S, Romano M, Maffei E, Fusaro M, Palumbo A, et al. Prognostic value of 64-slice coronary angiography in diabetes mellitus patients with known or suspected coronary artery disease compared with a nondiabetic population. Radiol Med. 2008;113(5):627-43.

9. Van Werkhoven JM, Cademartiri F, Seitun S, Maffei E, Palumbo A, Martini C, et al. Diabetes: prognostic value of CT coronary angiography-comparison with a nondiabetic population. Radiology. 2010;256(1):83-92.

10. Andreini D, Pontone G, Bartorelli AL, Agostoni P, Mushtaq S, Antonioli L, et al. Comparison of the diagnostic performance of 64-slice computed tomography coronary angiography in diabetic and non-diabetic patients with suspected coronary artery disease. Cardiovasc Diabetol. 2010;9:80.

11. Taylor AJ, Cerqueira M, Hodgson JM, Mark D, Min J, O'Gara P, et al. ACCF/ SCCT/ACR/AHA/ASE/ASNC/NASCI/SCAI/SCMR 2010 appropriate use criteria for cardiac computed tomography. A report of the American College of Cardiology Foundation Appropriate Use Criteria Task Force, the Society of Cardiovascular Computed Tomography, the American College of Radiology, the American Heart Association, the American Society of Echocardiography, the American Society of Nuclear Cardiology, the North American Society for Cardiovascular Imaging, the Society for Cardiovascular Angiography and Interventions, and the Society for Cardiovascular Magnetic Resonance. J Am Coll Cardiol. 2010;56(22):1864-94.

12. Johansen OE, Gullestad L, Blaasaas KG, Orvik E, Birkeland KI. Effects of structured hospital-based care compared with standard care for Type 2 diabetes-The Asker and Baerum Cardiovascular Diabetes Study, a randomized trial. Diabet Med. 2007;24(9):1019-27.

13. Gibbons RJ, Chatterjee K, Daley J, Douglas JS, Fihn SD, Gardin JM, et al. ACC/AHA/ACP-ASIM guidelines for the management of patients with chronic stable angina: a report of the American College of Cardiology/ American Heart Association Task Force on Practice Guidelines (Committee on Management of Patients With Chronic Stable Angina). J Am Coll Cardiol. 1999;33(7):2092-197.

14. World Health Organization. Definition, diagnosis and classification of diabetes mellitus and its complications - Part 1: Diagnosis and Classification of Diabetes Mellitus. Geneva: World Health Organization; 1999.

15. Halliburton SS, Abbara S, Chen MY, Gentry R, Mahesh M, Raff GL, et al. SCCT guidelines on radiation dose and dose-optimization strategies in cardiovascular CT. J Cardiovasc Comput Tomogr. 2011;5(4):198-224.

16. Agatston AS, Janowitz WR, Hildner FJ, Zusmer NR, Viamonte Jr M, Detrano R. Quantification of coronary artery calcium using ultrafast computed tomography. J Am Coll Cardiol. 1990;15(4):827-32.

17. Austen WG, Edwards JE, Frye RL, Gensini GG, Gott VL, Griffith LS, et al. A reporting system on patients evaluated for coronary artery disease. Report of the Ad Hoc Committee for Grading of Coronary Artery Disease, Council on Cardiovascular Surgery, American Heart Association. Circulation. 1975; 51 (4 Suppl):5-40.

18. Landis JR, Koch GG. The measurement of observer agreement for categorical data. Biometrics. 1977;33(1):159-74.

19. Youssef G, Budoff MJ. Coronary artery calcium scoring, what is answered and what questions remain. Cardiovasc Diagn Ther. 2012;2(2):94-105. 
20. Hou Y, Yue Y, Guo W, Feng G, Yu T, Li G, et al. Prospectively versus retrospectively ECG-gated 256-slice coronary CT angiography: image quality and radiation dose over expanded heart rates. Int J Cardiovasc Imaging. 2012;28(1):153-62.

21. Carrascosa P, Rodriguez-Granillo GA, Capunay C, Deviggiano A. Low-dose CT coronary angiography using iterative reconstruction with a 256-slice CT scanner. World J Cardiol. 2013;5(10):382-6.

22. Hou Y, Ma Y, Fan W, Wang Y, Yu M, Vembar M, et al. Diagnostic accuracy of low-dose 256-slice multi-detector coronary CT angiography using iterative reconstruction in patients with suspected coronary artery disease. Eur. Radiol. 2014;24(1):3-11.

23. Greenland $\mathrm{P}$, Bonow RO, Brundage BH, Budoff MJ, Eisenberg MJ, Grundy SM, et al. ACCF/AHA 2007 clinical expert consensus document on coronary artery calcium scoring by computed tomography in global cardiovascular risk assessment and in evaluation of patients with chest pain: a report of the American College of Cardiology Foundation Clinical Expert Consensus Task Force (ACCF/AHA Writing Committee to Update the 2000 Expert Consensus Document on Electron Beam Computed Tomography) developed in collaboration with the Society of Atherosclerosis Imaging and Prevention and the Society of Cardiovascular Computed Tomography. J Am Coll Cardiol. 2007;49(3):378-402.

24. Jiang B, Wang J, Lv X, Cai W. Dual-source CT versus single-source 64-section $\mathrm{CT}$ angiography for coronary artery disease: A meta-analysis. Clin Radiol. 2014;69(8):861-9.

25. Maffei E, Seitun S, Nieman K, Martini C, Guaricci Al, Tedeschi C, et al. Assessment of coronary artery disease and calcified coronary plaque burden by computed tomography in patients with and without diabetes mellitus. Eur Radiol. 2011;21(5):944-53.

26. Leber AW, Knez A, von Ziegler F, Becker A, Nikolaou K, Paul S, et al. Quantification of obstructive and nonobstructive coronary lesions by 64-slice computed tomography: a comparative study with quantitative coronary angiography and intravascular ultrasound. J Am Coll Cardiol. 2005;46(1):147-54

27. Mosseri M, Nahir M, Rozenman Y, Lotan C, Admon D, Raz I, et al. Diffuse narrowing of coronary arteries in diabetic patients: the earliest phase of coronary artery disease. Cardiology. 1998;89(2):103-10.

28. Elezi S, Kastrati A, Pache J, Wehinger A, Hadamitzky M, Dirschinger J, et al. Diabetes mellitus and the clinical and angiographic outcome after coronary stent placement. J Am Coll Cardiol. 1998;32(7):1866-73.

29. D'Ascenzo F, Cerrato E, Biondi-Zoccai G, Omede P, Sciuto F, Presutti DG, et al. Coronary computed tomographic angiography for detection of coronary artery disease in patients presenting to the emergency department with chest pain: a meta-analysis of randomized clinical trials. Eur Heart J Card Imaging. 2013;14(8):782-9.

30. Muhlestein JB, Lappe DL, Lima JA, Rosen BD, May HT, Knight S, et al. Effect of screening for coronary artery disease using $C T$ angiography on mortality and cardiac events in high-risk patients with diabetes: the FACTOR-64 randomized clinical trial. JAMA. 2014;312(21):2234-43.

31. Wiersma JJ, Verberne HJ, ten Holt WL, Radder IM, Dijksman LM, van Eck-Smit BL, et al. Prognostic value of myocardial perfusion scintigraphy in type 2 diabetic patients with mild, stable angina pectoris. J Nucl Cardiol. 2009;16(4):524-32.

32. George RT, Mehra VC, Chen MY, Kitagawa K, Arbab-Zadeh A, Miller JM, et al. Myocardial CT perfusion imaging and SPECT for the diagnosis of coronary artery disease: a head-to-head comparison from the CORE320 multicenter diagnostic performance study. Radiology. 2014;272(2):407-16.

33. Magalhaes TA, Kishi S, George RT, Arbab-Zadeh A, Vavere AL, Cox C, et al. Combined coronary angiography and myocardial perfusion by computed tomography in the identification of flow-limiting stenosis - The CORE320 study: An integrated analysis of CT coronary angiography and myocardial perfusion. J Cardiovasc Comput Tomogr. 2015;9(5):438-45.

34. Ofstad AP, Gullestad L, Orvik E, Aakhus S, Endresen K, Ueland T, et al. Interleukin-6 and activin A are independently associated with cardiovascular events and mortality in type 2 diabetes: the prospective Asker and Baerum Cardiovascular Diabetes (ABCD) cohort study. Cardiovasc Diabetol. 2013;12:126.

\section{Submit your next manuscript to BioMed Central and take full advantage of:}

- Convenient online submission

- Thorough peer review

- No space constraints or color figure charges

- Immediate publication on acceptance

- Inclusion in PubMed, CAS, Scopus and Google Scholar

- Research which is freely available for redistribution

Submit your manuscript at www.biomedcentral.com/submit 